\title{
Predicting and forecasting flow discharge at sites receiving significant lateral inflow
}

\author{
Gokmen Tayfur, ${ }^{1 *}$ Tommaso Moramarco ${ }^{2}$ and Vijay P. Singh ${ }^{3}$ \\ ${ }^{1}$ Department Civil Engineering, Izmir Institute of Technology, Urla, Izmir, 35340, Turkey \\ ${ }^{2}$ Research Institute for Hydrogeological Protection, National Research Council, Via Madonna Alta, 126, 06128 Perugia, Italy \\ ${ }^{3}$ Department of Civil and Environmental Engineering, Louisiana State University, Baton Rouge, LA 70803, USA
}

\begin{abstract}
:
Two models, one linear and one non-linear, were employed for the prediction of flow discharge hydrographs at sites receiving significant lateral inflow. The linear model is based on a rating curve and permits a quick estimation of flow at a downstream site. The non-linear model is based on a multilayer feed-forward back propagation (FFBP) artificial neural network (ANN) and uses flow-stage data measured at the upstream and downstream stations. ANN predicted the real-time storm hydrographs satisfactorily and better than did the linear model. The results of sensitivity analysis indicated that when the lateral inflow contribution to the channel reach was insignificant, ANN, using only the flow-stage data at the upstream station, satisfactorily predicted the hydrograph at the downstream station. The prediction error of ANN increases exponentially with the difference between the peak discharge used in training and that used in testing. ANN was also employed for flood forecasting and was compared with the modified Muskingum model (MMM). For a 4-h lead time, MMM forecasts the floods reliably but could not be applied to reaches for lead times greater than the wave travel time. Although ANN and MMM had comparable performances for an 8-h lead time, ANN is capable of forecasting floods with lead times longer than the wave travel time. Copyright (C) 2007 John Wiley \& Sons, Ltd.
\end{abstract}

KEY WORDS rating curve; ANN; feed-forward back propagation; modified Muskingum method; prediction; forecasting; flood hydrograph; flow stage; lead time

Received 17 March 2005; Accepted 24 February 2006

\section{INTRODUCTION}

Determination of flow discharge at a river site is required for water resource management and flood control. Discharge is computed from the measurement of flow depth, channel width, and flow velocity. For these measurements, the river section is equipped with hydrometric sensors for flow depth measurement, and cableway and current meter for velocity measurement. For channel cross-section, a topographic survey is carried out. Although the measurement of flow depth is simple and relatively inexpensive, velocity and channel cross-section measurements are not. For example, sampling of velocity points by current meter is quite difficult during severe floods, especially in the lower portion of the flow area (Moramarco et al., 2004). Furthermore, velocity measurements and channel cross-section surveys are expensive, especially at sites that are not easily accessible. This is one reason for relating flow discharge to flow depth.

Hydraulic modelling based on the Saint Venant equations is commonly used for translating discharge into flow depth, e.g. Hydrologic Engineering Centers River Analysis System (HEC-RAS) (U.S. Army Corps of Engineers, 1998). However, this requires topographic information on river cross-sections. For many rivers,

\footnotetext{
* Correspondence to: Gokmen Tayfur, Department Civil Engineering, Izmir Institute of Technology, Urla, Izmir, 35340, Turkey.

E-mail: gokmentayfur@iyte.edu.tr
}

topographic surveys neither exist nor are readily available. For this reason, many simplified approaches, such as the Jones formula (Henderson, 1966; Fenton, 1999) or the Muskingum method (Franchini and Lamberti, 1994), have been employed to relate the local stage to the discharge. However, these models involve parameters that are related to flood hydraulic characteristics. When lateral inflow is predominant during the evolution of flood, estimation of these parameters becomes difficult (Moramarco et al., 2005).

Moramarco et al. (2005) developed a practical model that can also be applied to cases in which lateral inflow is significant. It is especially useful when the downstream boundary condition is unknown or velocity measurements are available for low flows only. This model was also compared with the Muskingum model. The model of Moramarco et al. (2005) assumes a linear relation between the upstream and downstream flow variables and performs satisfactorily when the linearity is not unduly violated. This model, however, remains to be tested for cases in which the non-linearity between upstream and downstream flow variables is significant. Furthermore, it is desirable to have a model to simulate the non-linear flood process, especially when there is significant lateral inflow. Thus, the motivation for this study was to develop a non-linear artificial neural network (ANN) based on feed-forward back propagation (FFBP) for predicting the stage-discharge relationship. 
In addition, this study also deals with flood forecasting in real-time, where conceptual rainfall-runoff models of the semi-distributed type have been most reliable for operational purposes (Boyle et al., 2001; Michaud and Sorooshian, 1994). However, the complexity of the watershed system, the large number of parameters involved, and uncertainty in the determination of spatial resolution of each hydrologic process have led to the implementation of rather simple models (Boyle et al., 2001). One such approach is the Muskingum model (Franchini and Lamberti, 1994; Barbetta et al., 2003), but this model is not suitable where the lateral inflow contribution is significant and the rating curve is unknown (Moramarco et al., 2005). To overcome this difficulty, Barbetta et al. (2004) developed a modified Muskingum model (MMM). This is a 5-parameter model and the parameters are estimated by non-linear regression using upstream flow discharge hydrograph and downstream flow-stage data. Furthermore, MMM is limited to forecasting floods for lead times less than or equal to the flow wave travel time. Therefore, this study developed an ANN model to forecast real-time hourly flow hydrographs of individual storms.

Dawson and Wilby (1998) and Laio et al. (2003), among others, have also developed ANN models for flood forecasting. The ANN model in this study is different in that (1) it does not require rainfall data in the input vector, (2) it uses only semi-hourly flow-stage data measured at the upstream and downstream stations in the input vector, and (3) it does forecasting for individual storms at sites receiving significant lateral inflows.

Thus, the objective of this study is to (1) investigate the effectiveness of ANN in both predicting and forecasting hourly flow discharge hydrographs of individual storms in real-time at a downstream station using only hourly flowstage data measured at the upstream and downstream stations of a river reach receiving significant lateral inflow, and (2) to compare the ANN with the linear model of Moramarco et al. (2005) and the MMM for predicting and forecasting individual storm hydrographs. The models are evaluated using flood events measured at different gauging stations on the Tiber River in central Italy, which receives significant lateral inflows.

\section{ARTIFICIAL NEURAL NETWORKS FOR FLOOD PREDICTION AND FORECASTING}

ANNs have the ability to capture a relationship from given patterns and this makes them suitable for employment in the solution of large-scale complex problems, such as pattern recognition, non-linear modelling, classification, association, and control. ANNs are attractive for discharge prediction and flood forecasting because they can accommodate the non-linearity of the watershed runoff process and uncertainty in the parameter estimation, they have the capability to extract the relationship between input and output of the process without explicitly considering the physics of the process, they can find the relationships between different input samples, and they can generalize a relationship from small subsets of data while remaining robust in the presence of noisy or missing inputs. Because of these desiderata, they have been widely used in solving a range of hydrologic problems (ASCE Task Committee, 2000b). Tokar and Johnson (1999) developed an ANN to predict daily runoff as a function of daily precipitation, temperature, and snowmelt for a watershed in Maryland, USA. Tokar and Markus (2000) applied an ANN to predict monthly streamflow for the Fraser River Watershed in Colorado, USA. Using daily rainfall data, Rajurkar et al., (2002) applied an ANN for predicting daily flows during monsoon flood events for a large size catchment in India. Cigizoglu (2003) applied an ANN to estimate daily flow data of the rivers in the eastern part of the Mediterranean region of Turkey. Most of the ANNs employed only daily or monthly hydrometric data in the input vector for making long term predictions. ANNs have also been compared with regression using simple conceptual black box or stochastic models (ASCE Task Committee, 2000b; Rajurkar et al., 2002; Cigizoglu, 2003).

ANNs also have found wide application in forecasting studies. French et al. (1992) used an ANN to forecast rainfall intensity fields in space and time. Using real hydrometric data, Dawson and Wilby (1998) used an ANN to forecast flow rates for a 6-h lead time in two flood-prone catchments in the United Kingdom. They also carried out forecasting at a gauging station for longer periods (about 6 months) using rainfall and flow discharge data measured at the same station. Imrie et al. (2000) developed a cascade-correlation ANN to forecast flow rates for 4-h and 12-h lead times for two rivers in the catchment of river Trent in the United Kingdom using measured flow rates from 1996 to 1998. Similarly, using rainfall data in the input vector, Laio et al. (2003) performed a comparative study of forecasting flow stage at a gauging station on the Tanaro river in Alba in northwestern Italy. They compared the performances of ANN and NLP (non-linear prediction) for lead times of $1,3,6,12$, and $24 \mathrm{~h}$.

\section{MATHEMATICAL MODELS}

\section{Artificial neural networks (ANNs)}

In hydrologic applications, a three layer feed-forward type of ANN is commonly considered (Figure 1). In a feed-forward network, the input quantities are fed into input layer neurons, which, in turn, pass them on to the hidden layer neurons after multiplication by a weighted value. A hidden layer neuron adds up the weighted input received from each input neuron, associates it with a bias, and then passes on the result through a non-linear transfer function. The output neurons execute the same operation as performed by a hidden neuron. The back propagation algorithm finds the optimal weights by minimizing a predetermined error function $(E)$ of the following form 


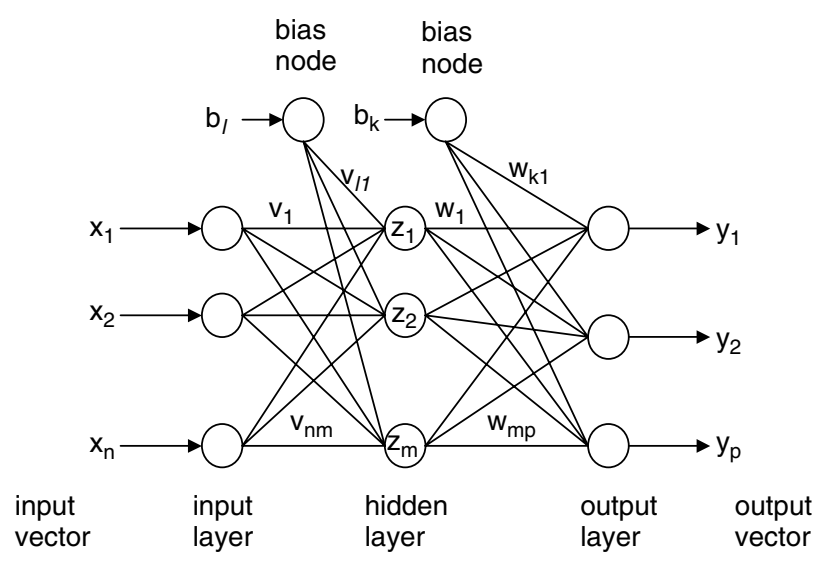

Figure 1. Representation of the three layer feed-forward ANN

(ASCE Task Committee, 2000a):

$$
E=\sum_{P} \sum_{p}\left(y_{i}-t_{i}\right)^{2}
$$

where $y_{i}=$ component of a network output vector $\boldsymbol{Y}$; $t_{i}=$ component of a target output vector $\boldsymbol{T} ; p=$ number of output neurons; and $P=$ number of training patterns.

In the back propagation algorithm, optimal weights would generate an output vector $\boldsymbol{Y}=\left(y_{1}, y_{2}, \ldots, y_{p}\right)$ as close as possible to the target values of the output vector $\boldsymbol{T}=\left(t_{1}, t_{2}, \ldots, t_{p}\right)$ with a selected accuracy. The back propagation algorithm employs the gradient-descent method, along with the chain rule of differentiation, to modify the network weights as follows (ASCE Task Committee, 2000a):

$$
v_{i j}{ }^{\text {new }}=v_{i j}{ }^{\text {old }}-\delta \frac{\partial E}{\partial v_{i j}}
$$

where $v_{i j}=$ weight from the $i$ th neuron in the previous layer to the $j$ th neuron in the current layer; and $\delta=$ learning rate.

The network learns by adjusting the biases and weights that link its neurons. Before training begins, a network's weights and biases are set equal to small random values. Also, owing to the nature of the sigmoid function used in the back propagation algorithm, all external input and output values are standardized before passing them into a neural network. Without standardization, input of large values into an ANN would require extremely small weighting factors to be applied, and this could cause a number of problems (Dawson and Wilby, 1998). The details of ANNs are available in the literature (ASCE Task Committee, 2000a).

\section{Rating curve method (RCM)}

The model of Moramarco et al. (2005), termed as the Rating Curve Method (RCM), is briefly summarized. Discharge at the downstream station is related to the measured flow variables at the upstream station as

$$
Q_{d}(t)=\alpha \frac{A_{d}(t)}{A_{u}\left(t-T_{L}\right)} Q_{u}\left(t-T_{L}\right)+\beta
$$

where $Q_{u}=$ the upstream discharge; $Q_{d}=$ the downstream discharge; $A_{d}$ and $A_{u}=$ the effective downstream and upstream cross sectional flow areas obtained from the observed stages, respectively; $T_{L}=$ the wave travel time depending on the wave celerity, $c$; and $\alpha$ and $\beta=$ model parameters (Moramarco et al., 2005).

Parameters $\alpha$ and $\beta$ are estimated from the following equations utilizing the base flow and peak discharge (Moramarco and Singh, 2001):

$$
\begin{aligned}
Q_{d}\left(t_{b}\right) & =\alpha \frac{A_{d}\left(t_{b}\right)}{A_{u}\left(t_{b}-T_{L}\right)} Q_{u}\left(t_{b}-T_{L}\right)+\beta \\
Q_{d}\left(t_{p}\right) & =\alpha \frac{A_{d}\left(t_{p}\right)}{A_{u}\left(t_{p}-T_{L}\right)} Q_{u}\left(t_{p}-T_{L}\right)+\beta
\end{aligned}
$$

where $Q_{d}\left(t_{b}\right)=$ base flow rate at the downstream section; $Q_{d}\left(t_{p}\right)=$ peak discharge at the downstream section; $t_{p}$ and $t_{b}=$ times when the peak stage and base flow occurs at the downstream section, respectively. In particular, $t_{b}$ is assumed to be the time just before the start of the rising limb of the hydrograph.

Once $Q_{d}\left(t_{b}\right)$ and $Q_{d}\left(t_{p}\right)$ are known, parameters $\alpha$ and $\beta$ are obtained from the solution of Equations (4) and (5) (Moramarco et al., 2005). The base flow at the downstream end, $Q_{d}\left(t_{b}\right)$, can be estimated through velocity measurements of low flow or it can be assumed that the velocity along the reach is constant when the base flow occurs (Moramarco et al., 2005). The peak discharge, $Q_{d}\left(t_{p}\right)$, is surmised as the contribution of two main elements: (i) the upstream discharge delayed for the wave travel time $T_{L}, Q_{u}\left(t_{p}-T_{L}\right)$, with its attenuation, $Q^{*}$, due to flood routing along the reach of length $L$; and (ii) the lateral inflows, $q_{p} L$, during the time interval $\left(t_{p}-T_{L}, t_{p}\right)$ :

$$
Q_{d}\left(t_{p}\right)=\left(Q_{u}\left(t_{p}-T_{L}\right)-Q^{*}\right)+q_{p} L
$$

In Equation (6), $T_{L}$ is implicitly assumed as the time required to match the rising limb and the peak region of the upstream and downstream dimensionless hydrographs. The flood attenuation $\left(Q^{*}\right)$ is computed from the Price formula (Raudkivi, 1979). The lateral inflow contribution, $q_{p} L$, is obtained from the characteristic form of the continuity equation (Moramarco et al., 2005). $q_{p}$ is estimated by assuming that, along the characteristics corresponding to the downstream peak stage, the following relationship holds (Moramarco and Singh, 2000):

$$
\frac{A_{d}\left(t_{p}\right)-A_{u}\left(t_{p}-T_{L}\right)}{T_{L}}=q_{p}
$$

\section{Modified Muskingum Method (MMM)}

A brief summary of the MMM, developed by Barbetta et al. (2004), is given here. When significant lateral inflow occurs along a reach, the Muskingum model expresses the discharge at the downstream end as

$$
Q_{d}(t+\Delta t)=k_{o} Q_{u}(t+\Delta t)+k_{1} Q_{u}(t)+k_{2} Q_{d}(t)
$$

where $k_{0}=\left(1+p_{l}\right) c_{0} ; k_{1}=\left(1+p_{l}\right) c_{1} ; k_{2}=c_{2}$, satisfying $k_{0}+k_{1}+k_{2}>1 ; c_{0}, c_{1}$, and $c_{2}$ are parameters 
depending upon the Muskingum coefficients $K$ and $x$ and the time step $\Delta t$ (Franchini and Lamberti, 1994) $\left(c_{\mathrm{o}}+c_{1}+c_{2}=1 \cdot 0 ; \quad c_{1}=\frac{K x+0.5 \Delta t}{K-K x+0.5 \Delta t}\right.$, and $c_{2}=$ $\frac{K-K x-0.5 \Delta t}{K-K x+0.5 \Delta t}$; subscripts $u$ and $d$ are for the upstream and downstream sections, respectively; $Q$ is the flow discharge; $t$ is time; and $q_{l}$ takes account of the lateral inflow contribution.

Assuming that the discharge is known only at the upstream hydrometric section, Equation (8) can be expressed in terms of flow stage at the downstream station $\left(h_{d}\right)$ using the kinematic wave relationship $Q=\lambda h^{\delta}$ for the downstream rating curve. The MMM can then be formulated in terms of water level, $h_{d}$, as

$$
\begin{aligned}
h_{d}(t+\Delta t)= & \left\{\frac { 1 } { \lambda } \left[\left(1+p_{l}\right) c_{0} Q_{u}(t+\Delta t)\right.\right. \\
& \left.\left.+\left(1+p_{l}\right) c_{1} Q_{u}(t)+c_{2} \lambda h_{d}^{\delta}(t)\right]\right\}^{1 / \delta}
\end{aligned}
$$

Since the aim is to produce a water level forecasting model, the term $Q_{u}(t+\Delta t)$ on the right-hand side of Equation (9) must be eliminated. To do so, it is sufficient to choose the time interval as $\Delta t=\Delta t^{*}=2 K x$ resulting in $c_{0}=0$. Thus, the final version of the MMM is obtained as follows (Barbetta et al., 2004):

$h_{d}\left(t_{f}+\Delta t^{*}\right)=\left\{\frac{1}{\lambda}\left[\left(1+p_{l}\right) c_{1}^{*} Q_{u}\left(t_{f}\right)+c_{2}^{*} \lambda h_{d}^{\delta}\left(t_{f}\right)\right]\right\}_{(10)}^{1 / \delta}$

where $c_{1}^{*}$ and $c_{2}^{*}$ are obtained when $\Delta t=\Delta t^{*}=2 K x$.

Parameters $\lambda, \delta, c_{1}^{*}, c_{2}^{*}$, and $p_{1}$ in Equation (10) are estimated by a non-linear regression technique using observations of downstream water level and upstream discharge. An adaptive scheme can be used to take account of the variability of lateral inflow during flood evolution, such as the one proposed in Barbetta et al. (2004).

\section{MODEL APPLICATION}

\section{Watershed}

The upper basin of Tiber river in central Italy, which has river reaches that are equipped, was selected for testing the linear and non-linear models for both prediction and flood forecasting. Figure 2 shows locations of the selected hydrometric sections along with the subtended drainage areas. Table I summarizes the main characteristics of the selected river reaches. Each gauged section is equipped with a remote ultrasonic water level gauge, and the velocity measurements are carried out by current meter.

\section{Hydrologic data}

Several accurate flow measurements were available, which allowed the estimation of the rating curve for each section (Moramarco et al., 2005). Of the seven severe storm events that occurred, four events (June 1997, May 1995, January 1997, February 2004) were chosen for

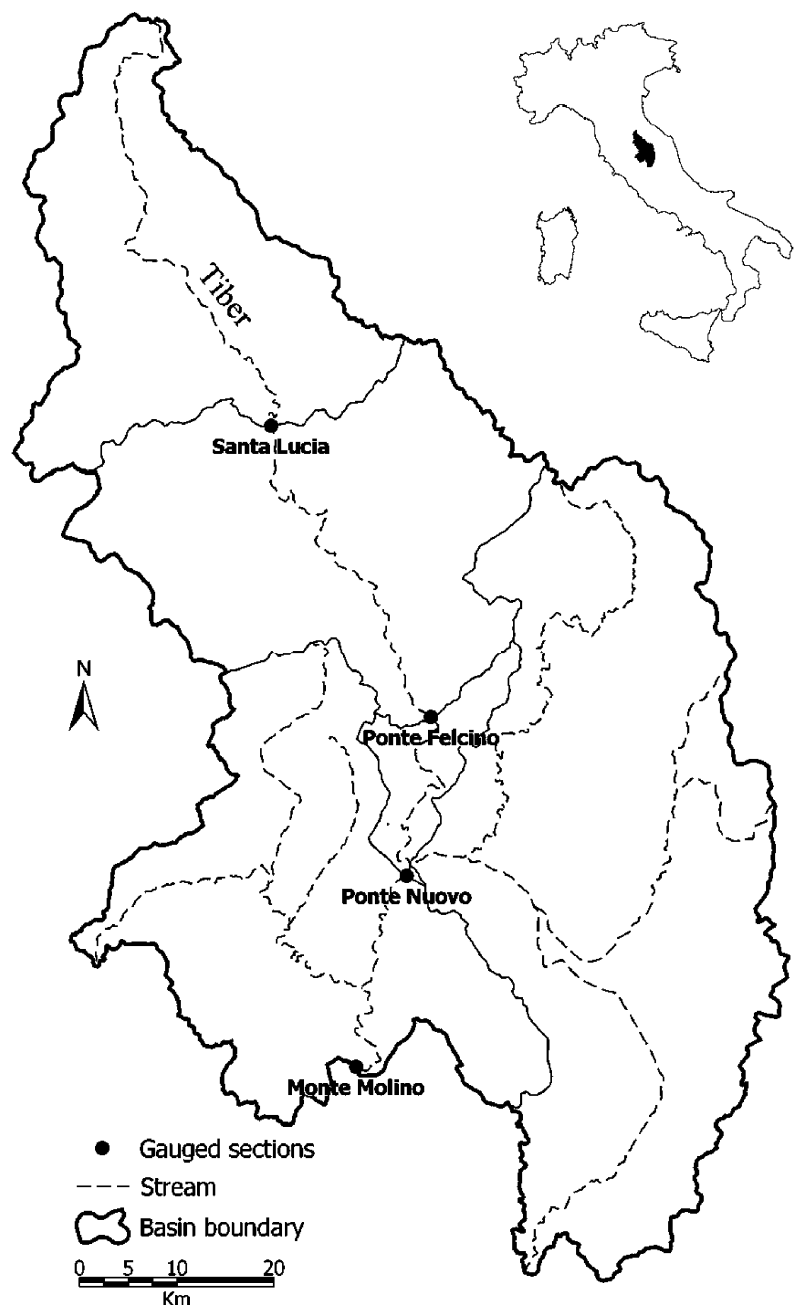

Figure 2. Upper Tiber river basin with the location of the gauging sites and the related subtended drainage areas

\begin{tabular}{|c|c|c|c|c|c|}
\hline River & $\begin{array}{c}\text { Bounded } \\
\text { sections } \\
\text { (2) }\end{array}$ & $\begin{array}{c}\text { Drainage } \\
\text { area } \\
\left(\mathrm{km}^{2}\right) \\
(3)\end{array}$ & $\begin{array}{c}\text { Reach } \\
\text { length } \\
(\mathrm{km}) \\
(4)\end{array}$ & $\begin{array}{l}\text { Mean } \\
\text { slope }\end{array}$ & $\begin{array}{c}\text { Mean } \\
\text { width } \\
\text { (m) } \\
(6)\end{array}$ \\
\hline Tiber & $\begin{array}{l}\text { Santa Lucia } \\
\text { Ponte Felcino }\end{array}$ & $\begin{array}{r}935 \\
2035\end{array}$ & $44 \cdot 6$ & 0.0016 & 35 \\
\hline Tiber & $\begin{array}{l}\text { Ponte Felcino } \\
\text { Monte Molino }\end{array}$ & $\begin{array}{l}2035 \\
5279\end{array}$ & $56 \cdot 2$ & 0.0009 & 50 \\
\hline
\end{tabular}

Table I. Geomorphologic characteristics of the river reaches

training the FFBP neural network model. The remaining three events were used for testing the model. The main properties of the selected flood events are summarized in Table II. It is seen that the lateral inflow contribution was significant in some of the events. Although the events for the training and testing groups in Table II were randomly chosen, special attention was paid to have testing events with hydrograph characteristics (e.g. base flow rate $Q_{b}$; peak flow rate $Q_{p}$; direct runoff volume $V$ ) that are comparable with those in the training set in order to avoid any bias in model predictions (Table II).

The river reach between the Santa Lucia and Ponte Felcino gauging stations (Figure 2) was considered for 
Table II. Main characteristics of the observed flood events at stations on Tiber river

\begin{tabular}{|c|c|c|c|c|c|c|c|}
\hline \multirow{2}{*}{$\begin{array}{l}\text { Date } \\
\text { (1) }\end{array}$} & \multicolumn{3}{|c|}{ Santa Lucia Station } & \multicolumn{3}{|c|}{ Ponte Felcino Station } & \multirow[b]{2}{*}{$\begin{array}{c}T_{L}(h) \\
(8)\end{array}$} \\
\hline & $\begin{array}{c}Q_{b} \\
\left(\mathrm{~m}^{3} \mathrm{~s}^{-1}\right) \\
(2)\end{array}$ & $\begin{array}{c}Q_{p} \\
\left(\mathrm{~m}^{3} \mathrm{~s}^{-1}\right) \\
(3)\end{array}$ & $\begin{array}{c}V \\
\left(10^{6} \mathrm{~m}^{3}\right) \\
(4)\end{array}$ & $\begin{array}{c}Q_{b} \\
\left(\mathrm{~m}^{3} \mathrm{~s}^{-1}\right) \\
(5)\end{array}$ & $\begin{array}{c}Q_{p} \\
\left(\mathrm{~m}^{3} \mathrm{~s}^{-1}\right) \\
(6)\end{array}$ & $\begin{array}{c}V \\
\left(10^{6} \mathrm{~m}^{3}\right) \\
(7)\end{array}$ & \\
\hline December 1990 & $8 \cdot 2$ & 418 & $49 \cdot 5$ & $9 \cdot 6$ & $404 \cdot 2$ & $59 \cdot 5$ & $2 \cdot 0$ \\
\hline January 1994 & $35 \cdot 6$ & 108 & 19 & $50 \cdot 8$ & 241 & $34 \cdot 7$ & 3.0 \\
\hline May $1995^{\mathrm{a}}$ & $4 \cdot 2$ & $71 \cdot 0$ & $10 \cdot 3$ & $8 \cdot 8$ & $138 \cdot 7$ & $19 \cdot 1$ & $4 \cdot 0$ \\
\hline January $1997^{\mathrm{a}}$ & $18 \cdot 2$ & $\begin{array}{l}120 \cdot 2 \\
146 \cdot 2\end{array}$ & $24 \cdot 3$ & $36 \cdot 2$ & $\begin{array}{l}225 \cdot 0 \\
359 \cdot 0\end{array}$ & $51 \cdot 8$ & $3 \cdot 5$ \\
\hline June $1997^{\mathrm{a}}$ & $5 \cdot 0$ & $345 \cdot 6$ & $27 \cdot 6$ & $10 \cdot 8$ & $449 \cdot 6$ & $49 \cdot 1$ & $5 \cdot 0$ \\
\hline January 2003 & 24 & 58 & $13 \cdot 5$ & 50 & 218 & $40 \cdot 9$ & $3 \cdot 5$ \\
\hline February $2004^{\mathrm{a}}$ & 22 & 91 & $7 \cdot 4$ & 55 & 276 & $27 \cdot 3$ & $3 \cdot 5$ \\
\hline
\end{tabular}

$Q_{b}$, base flow; $Q_{p}$, peak discharge; $V$, direct runoff volume; $T_{L}$, travel time.

${ }^{a}$ Used for ANN model training.

testing the models for flood prediction. The ANN model used the flow-stage data at Santa Lucia station (upstream station) and Ponte Felcino station (downstream station) to predict the flow discharge at Ponte Felcino station. The travel time between the two stations is about $4 \mathrm{~h}$. As pointed out earlier, since flow stage is an easily measurable variable, hydrologists prefer to relate flow rate to flow stage, as in the case of the RCM. This is why this study chose flow stage as an input variable to predict the flow rate in a river cross-section.

\section{Error criteria}

The prediction or forecasting error was computed as follows:

$$
\begin{aligned}
\text { Error }(\%)= & (\text { predicted quantity }- \text { observed quantity }) \\
& \times 100 / \text { observed quantity }
\end{aligned}
$$

Quantity may be the peak discharge or the time to peak. The error was assessed using the persistence coefficient defined as follows (Kitanidis and Bras, 1980):

$$
C_{p}=1-\frac{\sum\left[Q_{d}^{o}(t)-Q_{d}^{p}(t)\right]^{2}}{\sum\left[Q_{d}^{o}(t)-Q_{d}^{o}(t-\Delta t)\right]^{2}}
$$

where $C_{p}=$ the persistence coefficient; $Q_{d}^{o}(t)=$ the observed discharge at the downstream station at time $t ; Q_{d}^{p}(t)=$ the predicted discharge at the downstream station at time $t$; and $\Delta t=$ the forecasting lead time. If $C_{p}=1$, then the performance of the proposed model for forecasting is perfect. If $C_{p}=0$, then there is no need to use the proposed model for forecasting.

\section{Flood hydrograph prediction}

ANN model training. ANN was trained with a learning rate of 0.01 and 2000 iterations. The network had 2 neurons in the input layer, 5 neurons in the inner layer, and 1 neuron in the output layer. Input neurons represent flow stage at the upstream and downstream points while output neuron is for the flow rate at the downstream location. Before training was initiated, all the data fed into the network were standardized and small random values were assigned for the network's weights and biases. Further details are given by Tayfur (2002). The number of neurons in the hidden layer was decided by the commonly employed trial and error procedure. For this purpose, the mean error (ME) and mean relative error (MRE) were used as the error measures. Accordingly, the number of iterations that provided the minimum $\mathrm{ME}$ and MRE values was the criteria for terminating the iterations. For example, for this particular problem of flood hydrograph prediction application, the values of the error measures started with $\mathrm{ME}=181.7 \mathrm{~m}^{3} \mathrm{~s}^{-1}$ and $\mathrm{MRE}=63.4$ at the first iteration and then rapidly decreased to $31.1 \mathrm{~m}^{3} \mathrm{~s}^{-1}$ and 32.4 , respectively, after the 100th iteration. The errors then gradually decreased and stabilized at $\mathrm{ME}=10.4 \mathrm{~m}^{3} \mathrm{~s}^{-1}$ and $\mathrm{MRE}=16.5$ after 2000 iterations.

Model testing: hydrograph prediction. The trained ANN and the linear RCM were applied to predict the hydrographs of the three testing events (December 1990, January 1994, January 2003) measured at the Ponte Felcino station (Table II). Figure $3 a-c$ show the predicted hydrographs. It is seen that ANN satisfactorily predicted the hydrographs in terms of the overall trend, time to peak, and peak discharges. Overall, it yielded better results than did the RCM, which generally overestimated the discharge. For the two-peak hydrograph of January 2003 (Figure 3c), ANN under-predicted the lower peak but closely captured the higher peak, whereas RCM predicted the lower peak better, but over-predicted the higher peak. The percentage error in peak discharge and time to peak was computed for each event and is given in Table III. Note that a negative error value indicates underestimation whereas a positive value indicates overestimation. ANN predicted the peak discharge of each event with less than 5\% error whereas RCM had more than $10 \%$ error. For the January 2003 event, RCM over-predicted the peak discharge with about $24 \%$ error whereas ANN had 5\% error. The time to peak was accurately predicted by ANN whereas RCM had about $4 \%$ error. 

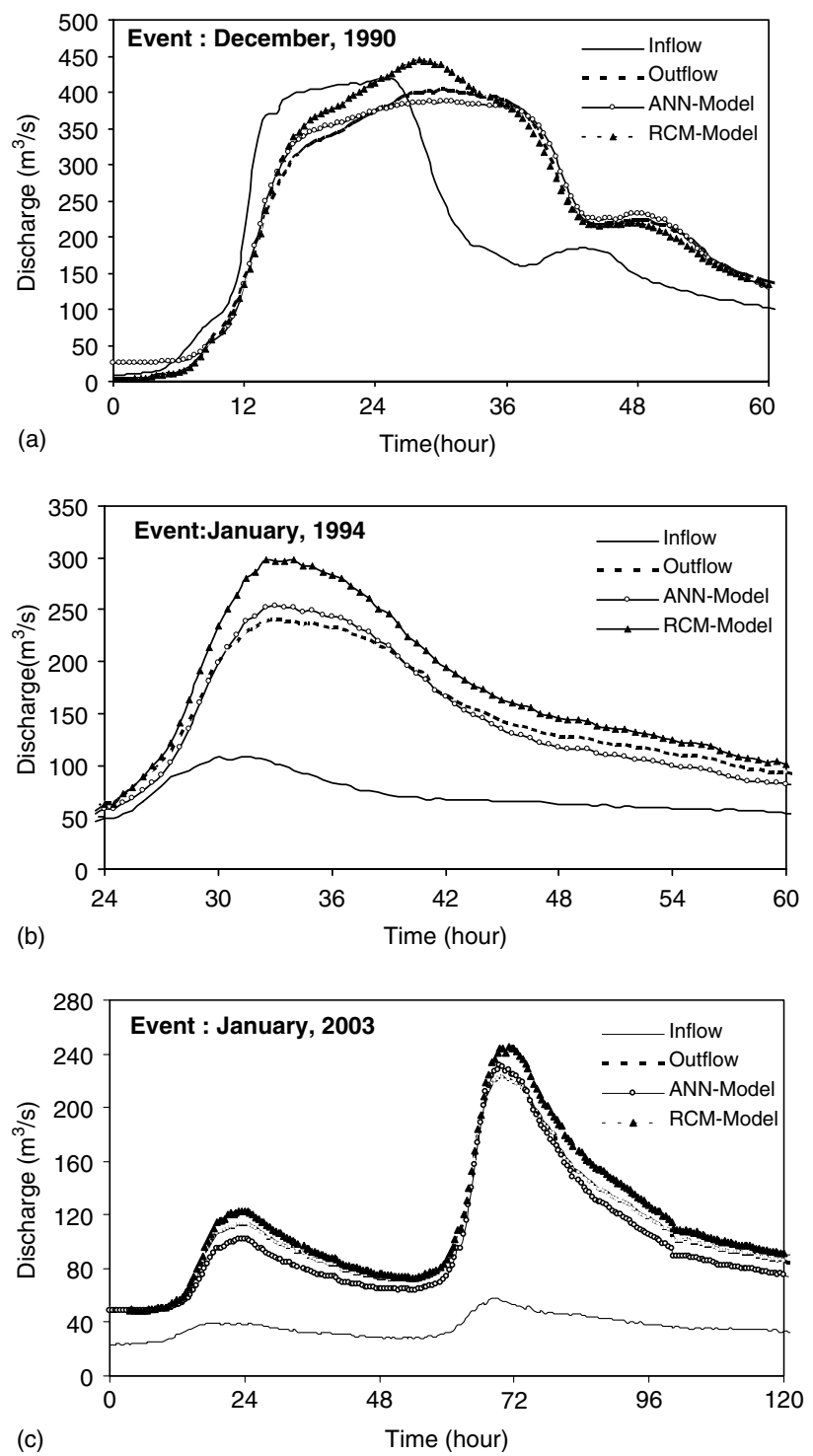

Figure 3. ANN and RCM model simulations of the flood hydrographs measured at the Ponte Felcino gauging station on (a) December 1990, (b) January 1994, and (c) January 2003

Table III. Percentage errors in peak discharge, $E_{Q p}$, and time to peak, $E_{T p}$

\begin{tabular}{lrrrrr}
\hline Event & \multicolumn{2}{c}{$E_{Q p}(\%)$} & & \multicolumn{2}{c}{$E_{T p}(\%)$} \\
\cline { 2 - 3 } \cline { 6 - 6 } & ANN & RCM & & ANN & RCM \\
\hline December 1990 & $-4 \cdot 2$ & 9.9 & & $0 \cdot 0$ & $-6 \cdot 7$ \\
January 1994 & $3 \cdot 1$ & $9 \cdot 4$ & & $0 \cdot 0$ & $2 \cdot 2$ \\
January 2003 & $5 \cdot 4$ & $23 \cdot 7$ & & $0 \cdot 0$ & $3 \cdot 0$ \\
Average & $4 \cdot 2$ & $14 \cdot 3$ & & $0 \cdot 0$ & $4 \cdot 0$ \\
\hline
\end{tabular}

Sensitivity analysis. For sensitivity analysis, ANN was evaluated using only the flow-stage data measured at the upstream station as input and predicting the discharge at the downstream station. For this purpose, the ANN network had 1 neuron in the input layer and 4 neurons in the hidden layer. The network was trained with a 0.01 learning rate and 2000 iterations. The storm events in Table II were used for ANN training and testing. Figure $4 \mathrm{a}-\mathrm{c}$
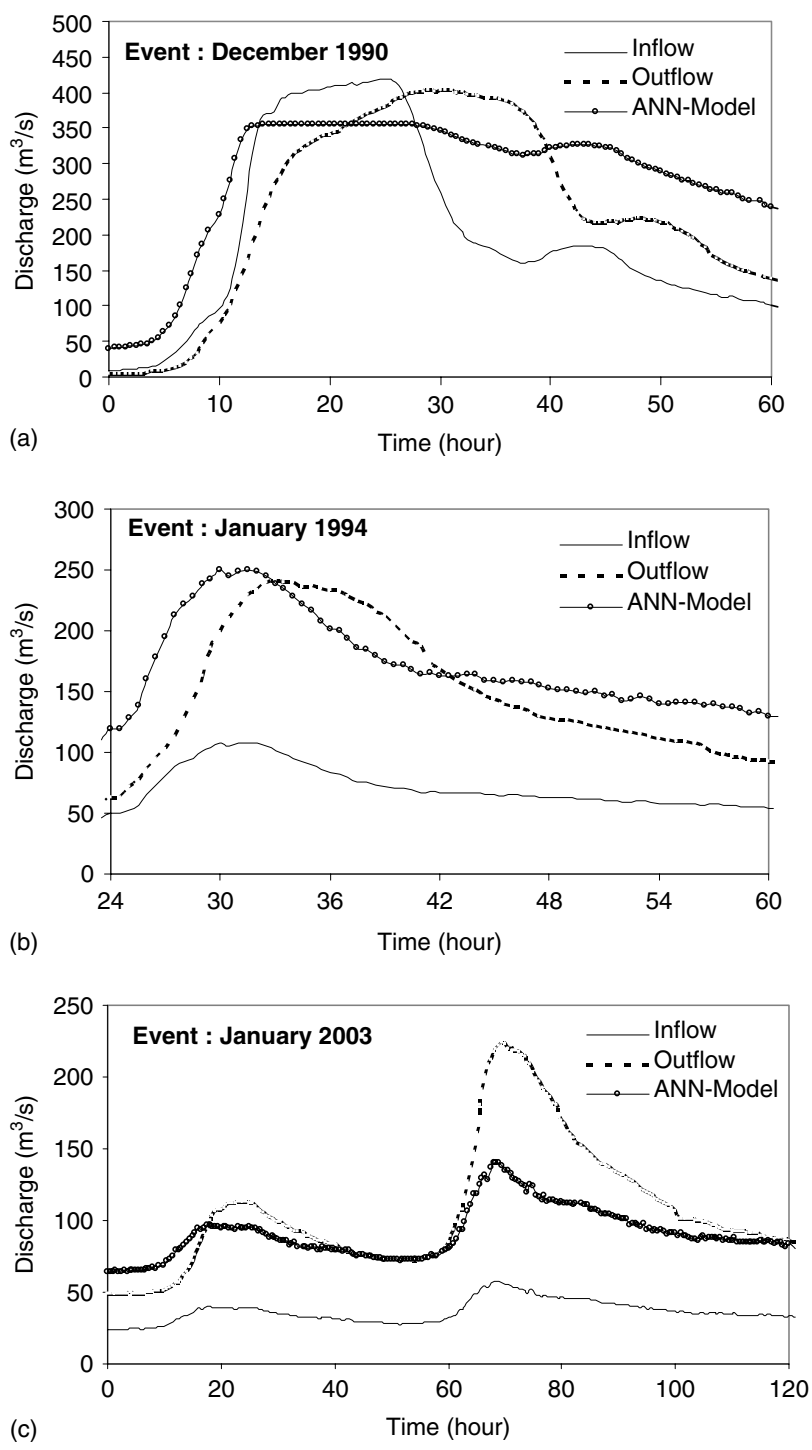

Figure 4. ANN model simulations of the flood hydrographs measured at the Ponte Felcino gauging station on (a) December 1990, (b) January 1994, and (c) January 2003 (The network input is the flow discharge measured at the Santa Lucia station)

show the predicted and measured hydrographs. ANN captures the magnitude of peak discharge with delay in each case in which there is insignificant lateral inflow into the channel reach (Figure $4 \mathrm{a}$ and $\mathrm{b}$ ). On the other hand, the model poorly predicts the hydrograph when there is significant lateral inflow into the channel reach (Figure 4c). The model prediction error for each event is given in Table IV. When lateral inflow is not significant, the model under-predicts the discharge with delay, with an error of about $10 \%$. If lateral inflow is significant, the prediction error in peak discharge reaches $40 \%$ (Figure 4c, Table IV). This result indicates that when the contribution of lateral inflow to the channel reach is not significant, the ANN model may be employed using only the flow-stage data at the upstream station for predicting the hydrograph at a downstream station.

Extrapolation. The extrapolation capability of ANN for predicting peak discharge outside the range of values 
Table IV. Percentage errors in peak discharge, $E_{Q p}$, and time to peak, $E_{T p}$ (flow stage at the upstream station is the only ANN model input)

\begin{tabular}{lrr}
\hline Event & $E_{Q p}(\%)$ & $E_{T p}(\%)$ \\
\hline December 1990 & $-12 \cdot 1$ & $-15 \cdot 0$ \\
January 1994 & $4 \cdot 1$ & -4.5 \\
January 2003 & -37.5 & -2.2 \\
Average & 17.9 & $7 \cdot 2$ \\
\hline
\end{tabular}

employed in network training was investigated. The purpose here was to calculate the error of ANN in predicting hydrographs with higher peaks when a hydrograph with a lower peak was used in training. Table V summarizes three different cases and the events used therein for this purpose, and Table VI presents the main characteristics of these events. In Case-I, a hydrograph with a peak, $Q_{\max }=230 \mathrm{~m}^{3} \mathrm{~s}^{-1}$, was used in network training and the other 11 events were used for prediction. Similarly, in Case-II, a hydrograph with a peak, $Q_{\max }=322 \mathrm{~m}^{3} \mathrm{~s}^{-1}$, was used in training and hydrographs of the other nine events were predicted. Finally, in Case-III, a hydrograph with a peak, $Q_{\max }=404 \mathrm{~m}^{3} \mathrm{~s}^{-1}$, was used in network training and hydrographs of the other six events were predicted. In each case, ANN had 2 neurons in the input layer, 5 neurons in the inner layer, and 1 neuron in the output layer. Input layer neurons stand for flow stage at the upstream and downstream stations while the output neuron is for the outflow rate at the downstream station. The network was trained with a 0.01 learning rate and 2000 iterations. The percent error with regard to peak discharge predictions is presented in Figure 5. The prediction error (percent) in peak discharge in each case varies exponentially with the difference between the peak discharge used in training and the peak discharge used in testing. It is seen from Figure 5 that when an event whose peak discharge is $100 \mathrm{~m}^{3} \mathrm{~s}^{-1}$ is used in network training to predict an event whose peak discharge is $200 \mathrm{~m}^{3} \mathrm{~s}^{-1}$, peak discharge will be under-predicted with a $50 \%$ error.
The prediction error would be about 10,15 , or $25 \%$ if the peak discharge to be predicted were 110, 120, or $140 \mathrm{~m}^{3} \mathrm{~s}^{-1}$, respectively. Furthermore, using a single event with a low peak in network training would yield better prediction of the events with higher peaks than if more events with lower peaks were used in network training. This is because ANN tends to further underestimate peak discharge if hydrographs with lower peaks are used in training. Imrie et al. (2000) developed modified a cascade-correlation training algorithm to improve the extrapolation capability of ANNs.

\section{Flood hydrograph forecasting}

ANN training. ANN was trained using six (January 1986, February 1991, December 1995, January 1997, March 2000, February 2004) events for a 4-h lead forecast time. Using flow-stage data at the Santa Lucia upstream station and Ponte Felcino downstream station for network training, flood discharge was forecast at the Ponte Felcino downstream station with a lead time of $4 \mathrm{~h}$. ANN had 2 neurons in the input layer, 5 neurons in the hidden layer, and 1 neuron in the output layer. Input layer neurons stand for flow stage at the upstream and downstream stations while the output layer neuron represents outflow rate at the downstream station. The optimal number of neurons in the inner layer was found by trial and error procedure, as described earlier. The model was trained with a 0.01 learning rate and 2000 iterations.

For 8-h and 12-h lead time flood forecasting, the reach of the Tiber river between Ponte Felcino and Monte Molino (Figure 2) was considered. The wave travel time of the reach is approximately $8 \mathrm{~h}$. Six events (marked with $\left(^{*}\right)$ in Table VII) were used for model training. The table summarizes the main characteristics of these storm events. Using the flow-stage data measured at the upstream gauging station of Ponte Felcino and downstream gauging station of Monte Molino, 8-h and 12-h lead time flow discharges were forecast at the Monte

Table V. Events used for the ANN peak discharge extrapolation

\begin{tabular}{|c|c|c|c|c|c|}
\hline \multicolumn{2}{|c|}{ CASE 1} & \multicolumn{2}{|c|}{ CASE-II } & \multicolumn{2}{|c|}{ CASE-III } \\
\hline Training event & $Q_{\max }$ & Training event & $Q_{\max }$ & Training event & $Q_{\max }$ \\
\hline March 2000 & $230 m^{3} s^{-1}$ & November 1997 & $322 m^{3} s^{-1}$ & December 1990 & $404 m^{3} s^{-1}$ \\
\hline Testing events & $Q_{\max }\left(\mathrm{m}^{3} \mathrm{~s}^{-1}\right)$ & Testing events & $Q_{\max }\left(\mathrm{m}^{3} \mathrm{~s}^{-1}\right)$ & Testing events & $Q_{\max }\left(\mathrm{m}^{3} \mathrm{~s}^{-1}\right)$ \\
\hline January 94 & 240 & January 86 & 548 & January 86 & 548 \\
\hline November 97 & 322 & December 96 & 373 & April 97 & 437 \\
\hline December 96 & 373 & December 90 & 404 & February 91 & 593 \\
\hline December 90 & 404 & April 97 & 437 & December 95 & 424 \\
\hline April 97 & 437 & February 91 & 593 & June 97 & 450 \\
\hline January 86 & 548 & December 95 & 424 & February 99 & 429 \\
\hline February 91 & 593 & January 97 & 359 & & \\
\hline December 95 & 424 & June 97 & 450 & & \\
\hline January 97 & 359 & February 99 & 429 & & \\
\hline June 97 & 450 & & & & \\
\hline February 99 & 429 & & & & \\
\hline
\end{tabular}


Table VI. Main characteristics of the observed flood events at stations on Tiber river

\begin{tabular}{|c|c|c|c|c|c|c|c|}
\hline \multirow{2}{*}{$\begin{array}{l}\text { Date } \\
\text { (1) }\end{array}$} & \multicolumn{3}{|c|}{ Santa Lucia section } & \multicolumn{3}{|c|}{ Ponte Felcino section } & \multirow{2}{*}{$\begin{array}{r}T_{L}(h) \\
(8)\end{array}$} \\
\hline & $\begin{array}{c}Q_{b} \\
\left(\mathrm{~m}^{3} \mathrm{~s}^{-1}\right) \\
(2)\end{array}$ & $\begin{array}{c}Q_{p} \\
\left(\mathrm{~m}^{3} \mathrm{~s}^{-1}\right) \\
(3)\end{array}$ & $\begin{array}{c}V \\
\left(10^{6} \mathrm{~m}^{3}\right) \\
(4)\end{array}$ & $\begin{array}{c}Q_{b} \\
\left(\mathrm{~m}^{3} \mathrm{~s}^{-1}\right) \\
(5)\end{array}$ & $\begin{array}{c}Q_{p} \\
\left(\mathrm{~m}^{3} \mathrm{~s}^{-1}\right) \\
(6)\end{array}$ & $\begin{array}{c}V \\
\left(10^{6} \mathrm{~m}^{3}\right) \\
(7)\end{array}$ & \\
\hline January 1986 & $13 \cdot 0$ & $412 \cdot 2$ & $45 \cdot 2$ & $5 \cdot 3$ & $548 \cdot 3$ & $76 \cdot 2$ & $4 \cdot 0$ \\
\hline December 1990 & $8 \cdot 2$ & 418 & $49 \cdot 6$ & $9 \cdot 6$ & 404 & 59.5 & $2 \cdot 0$ \\
\hline February 1991 & $27 \cdot 7$ & 276 & $27 \cdot 8$ & $22 \cdot 9$ & 600 & $58 \cdot 5$ & $4 \cdot 0$ \\
\hline January 1994 & $35 \cdot 6$ & 103 & 19 & $47 \cdot 8$ & 271 & 34.7 & $3 \cdot 0$ \\
\hline December 1995 & $4 \cdot 2$ & $71 \cdot 0$ & $10 \cdot 3$ & $8 \cdot 8$ & $138 \cdot 7$ & $19 \cdot 1$ & $4 \cdot 0$ \\
\hline December 1996 & $14 \cdot 0$ & 282.7 & $18 \cdot 8$ & $12 \cdot 5$ & 373.5 & $29 \cdot 7$ & $4 \cdot 0$ \\
\hline January 1997 & $18 \cdot 2$ & $\begin{array}{l}120 \cdot 2 \\
146 \cdot 2\end{array}$ & $24 \cdot 3$ & $36 \cdot 2$ & $\begin{array}{l}225 \cdot 0 \\
359 \cdot 0\end{array}$ & $51 \cdot 8$ & $3 \cdot 5$ \\
\hline April 1997 & $3 \cdot 7$ & $366 \cdot 0$ & $32 \cdot 8$ & $11 \cdot 7$ & 437.7 & $57 \cdot 7$ & $4 \cdot 0$ \\
\hline June 1997 & $5 \cdot 0$ & $345 \cdot 6$ & $27 \cdot 6$ & $10 \cdot 8$ & $449 \cdot 6$ & $49 \cdot 1$ & $5 \cdot 0$ \\
\hline November 1997 & $7 \cdot 8$ & $108 \cdot 6$ & $6 \cdot 6$ & $45 \cdot 7$ & $322 \cdot 5$ & $24 \cdot 3$ & $3 \cdot 5$ \\
\hline February 1999 & $19 \cdot 0$ & $229 \cdot 0$ & $15 \cdot 2$ & $25 \cdot 4$ & $429 \cdot 2$ & 39.4 & $4 \cdot 0$ \\
\hline March 2000 & $19 \cdot 4$ & $53 \cdot 3$ & $4 \cdot 6$ & $31 \cdot 8$ & $230 \cdot 3$ & $20 \cdot 9$ & $4 \cdot 0$ \\
\hline
\end{tabular}

$Q_{b}$, base flow; $Q_{p}$, peak discharge; $V$, direct runoff volume; $T_{L}$, travel.

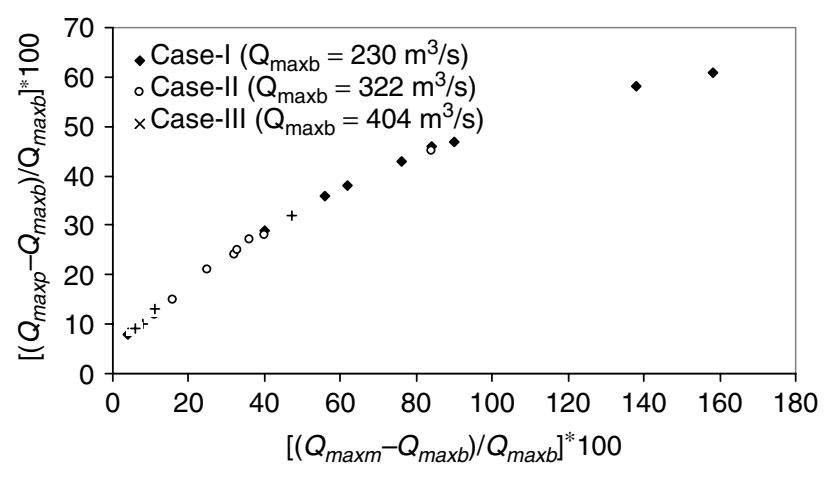

Figure 5. ANN peak discharge extrapolation error results $\left(Q_{\max b}=\right.$ peak discharge of the hydrograph used for network training, $Q_{\max p}=$ peak discharge of a hydrograph that is predicted by ANN model during the testing stage, and $Q_{\max m}=$ measured peak discharge of the hydrograph predicted by ANN during the testing stage)

Molino downstream station. The constructed ANN had 2 neurons in the input layer, 12 neurons in the inner layer, and 1 neuron in the output layer. Input layer neurons stand for flow stage at the upstream and downstream stations while the output layer neuron represents the outflow rate at the downstream station. The optimal number of neurons in the hidden layer was found by trial and error, as described earlier. The network was trained with a 0.005 learning rate and 10000 iterations. Note that the applicability of ANN for forecasting in actual practice might be somewhat limited as the input data consists of only river stage at the upstream and downstream stations. However, when hydrologists are provided with such easily measurable data, it would be easier to perform the forecasting by ANN and thereby forewarn the responsible authorities for taking precautionary measures for mitigating possible flood damages.

Table VII. Main characteristics of the observed flood events at stations on Tiber river

\begin{tabular}{|c|c|c|c|c|c|c|c|}
\hline \multirow{2}{*}{$\begin{array}{l}\text { Date } \\
\text { (1) }\end{array}$} & \multicolumn{3}{|c|}{ Ponte Felcino } & \multicolumn{3}{|c|}{ Monte Molino } & \multirow{2}{*}{$\begin{array}{l}T_{L} \\
(h) \\
\\
(8)\end{array}$} \\
\hline & $\begin{array}{c}Q_{b} \\
\left(\mathrm{~m}^{3} \mathrm{~s}^{-1}\right) \\
(2)\end{array}$ & $\begin{array}{c}Q_{p} \\
\left(\mathrm{~m}^{3} \mathrm{~s}^{-1}\right) \\
(3)\end{array}$ & $\begin{array}{c}V \\
\left(10^{6} \mathrm{~m}^{3}\right) \\
(4)\end{array}$ & $\begin{array}{c}Q_{b} \\
\left(\mathrm{~m}^{3} \mathrm{~s}^{-1}\right) \\
(5)\end{array}$ & $\begin{array}{c}Q_{p} \\
\left(\mathrm{~m}^{3} \mathrm{~s}^{-1}\right) \\
(6)\end{array}$ & $\begin{array}{c}V \\
\left(10^{6} \mathrm{~m}^{3}\right) \\
(7)\end{array}$ & \\
\hline December $1998^{a}$ & 18 & 120 & $8 \cdot 2$ & 90 & 837 & $61 \cdot 2$ & $6 \cdot 5$ \\
\hline February 1999 & $25 \cdot 4$ & 430 & 39.4 & 45 & 814 & $66 \cdot 2$ & 8 \\
\hline April 1999 & 21 & 171 & $31 \cdot 4$ & 68 & 350 & $117 \cdot 7$ & 8 \\
\hline November $1999^{a}$ & 48 & $\begin{array}{l}120 \\
239\end{array}$ & $31 \cdot 8$ & 94 & $\begin{array}{l}400 \\
450\end{array}$ & $85 \cdot 3$ & $6 \cdot 5$ \\
\hline December $1999^{a}$ & 25 & 165 & $21 \cdot 1$ & 73 & 984 & $125 \cdot 6$ & $4 \cdot 5$ \\
\hline March 2000 & 22 & 162 & $39 \cdot 1$ & 39 & 450 & $82 \cdot 2$ & $8 \cdot 5$ \\
\hline December 2000 & 5 & 525 & 114 & 28 & 927 & $224 \cdot 7$ & 7 \\
\hline January $2001^{\mathrm{a}}$ & 45 & $\begin{array}{l}279 \\
169\end{array}$ & $36 \cdot 1$ & 123 & $\begin{array}{l}409 \\
372\end{array}$ & $65 \cdot 9$ & 8 \\
\hline March $2001^{\mathrm{a}}$ & 26 & 191 & $17 \cdot 2$ & 80 & 399 & 37 & $6 \cdot 5$ \\
\hline April 2001 ${ }^{\mathrm{a}}$ & 22 & 224 & $16 \cdot 3$ & 68 & 288 & $26 \cdot 2$ & 8 \\
\hline
\end{tabular}

$Q_{b}$, base flow; $Q_{p}$, peak discharge; $V$, direct runoff volume; $T_{L}$, travel.

${ }^{a}$ Used for model training. 

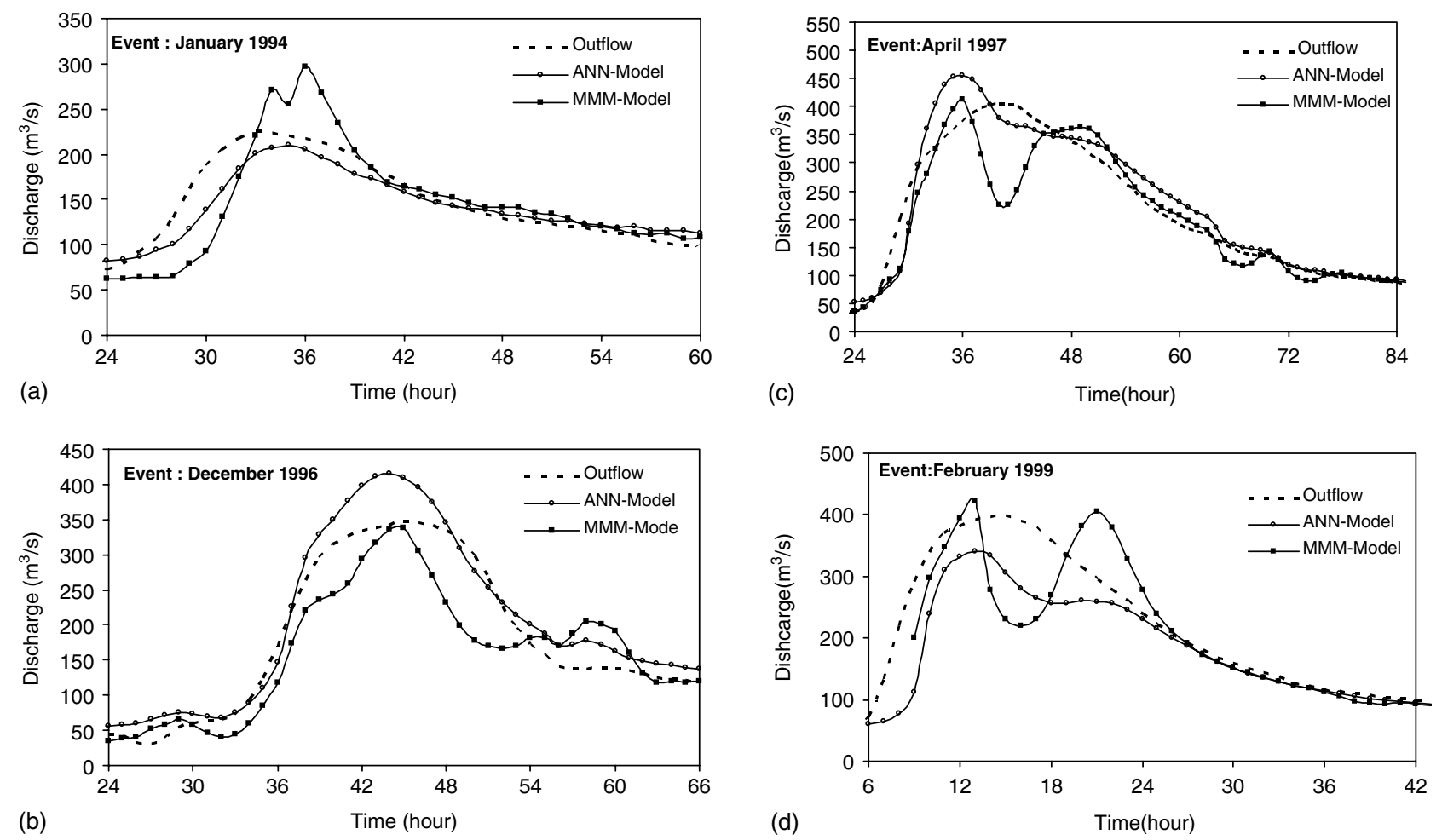

Figure 6. Forecasting storm hydrographs of (a) January 1994, (b) December 1996, (c) April 1997, and (d) February 1999 by ANN and MMM models with a 4-h lead time (Santa Lucia-Ponte Felcino Reach)

Model testing: forecasting. The ANN and MMM developed here were applied to forecast flood hydrographs with different lead times. It was noted that RCM cannot be employed for flood forecasting because information on the time to peak and peak discharge of a hydrograph measured at a downstream station is needed for estimation of its parameters $\alpha$ and $\beta$. Four events (January 1994, December 1996, April 1997, February 1999) were used for model testing. Figure $6 \mathrm{a}-\mathrm{d}$ show the model forecasting results for a 4-h lead time. It is seen that ANN, in general, made satisfactory forecasts of storm hydrographs. In general, it outperformed the MMM, whose discharge forecasts were irregular and sometimes fluctuating, and otherwise provided smooth hydrographs. For example, for the storm events of April 1997 and February 1999, fluctuations in the hydrograph forecast by MMM were pronounced, as shown in Figure $6 \mathrm{c}$ and $\mathrm{d}$. The forecast errors of ANN and MMM for a 4-h lead time are given in Table VIII. It is seen that both models, on average, produced comparable errors that hovered around $10 \%$ in the time to peak and peak discharge. However, ANN has a higher value of the persistence coefficient than does MMM. Although the error produced by MMM were comparable to that produced by ANN, it could not capture the hydrograph trends, especially for the hydrographs of April 1997 and February 1999 (Figure 6c and d). The results presented in Figure $6 \mathrm{a}-\mathrm{d}$ and Table VIII indicate that ANN can be employed for flood forecasting for a 4-h lead time.

Four flood events measured at the Ponte Felcino and Monte Molino gauging stations were used for testing the ANN. These events are summarized in Table VII.
Table VIII. Percentage errors in peak discharge, $E_{Q p}$, time to peak, $E_{T p}$, and persistence coefficient $\left(C_{p}\right)$ for 4-h lead time flood forecasts (Santa Lucia-Ponte Felcino Reach)

\begin{tabular}{|c|c|c|c|c|c|c|}
\hline \multirow[b]{2}{*}{ Event } & \multicolumn{2}{|c|}{$E_{Q p}(\%)$} & \multicolumn{2}{|c|}{$E_{T p}(\%)$} & \multicolumn{2}{|c|}{$C_{p}$} \\
\hline & ANN & MMM & ANN & MMM & ANN & MMM \\
\hline January 1994 & $-6 \cdot 7$ & $31 \cdot 6$ & $6 \cdot 1$ & $9 \cdot 1$ & 0.46 & $0 \cdot 23$ \\
\hline December 1996 & $19 \cdot 6$ & $-2 \cdot 6$ & $-2 \cdot 2$ & $0 \cdot 0$ & $0 \cdot 76$ & 0.53 \\
\hline April 1997 & $12 \cdot 1$ & $1 \cdot 2$ & $-10 \cdot 0$ & $-10 \cdot 0$ & $0 \cdot 60$ & $0 \cdot 34$ \\
\hline February 1999 & $-14 \cdot 3$ & $6 \cdot 0$ & $-13 \cdot 3$ & $-40 \cdot 0$ & 0.63 & 0.44 \\
\hline Average & $13 \cdot 2$ & $10 \cdot 4$ & $7 \cdot 9$ & $14 \cdot 8$ & $0 \cdot 61$ & $0 \cdot 39$ \\
\hline
\end{tabular}

Figure $7 \mathrm{a}-\mathrm{d}$ present the results of the 8 -h lead time flood forecasting. Both ANN and MMM performed satisfactorily. ANN captured the peak of each hydrograph but overestimated the lower peak of the two-peak hydrograph (Figure 7d), whereas in two cases MMM underestimated the peaks (Figure 7a and d). ANN captured the peak of the storm hydrograph of February 1999 while overestimating the recession limb, and MMM underestimated the entire hydrograph (Figure 7a). Both models captured the peaks of the storm event of April 1999 while MMM closely forecast the entire hydrograph (Figure $7 \mathrm{~b}$ ). Both the models captured the peak of the March 2000 hydrograph, whereas ANN over-predicted the rising limb and MMM underestimated it (Figure 7c). Table IX presents the error for each 8-h lead time flood forecast. It is seen that both models have comparable errors (less than 5\%) with respect to the time to peak and peak discharge forecasts. On the other hand, MMM has a higher value of persistence coefficient $\left(C_{p}\right)$ than ANN for each storm 



Figure 7. Forecasting storm hydrographs of (a) February 1999, (b) April 1999, (c) March 2000, and (d) December 2000 by ANN and MMM models with an 8-h lead time (Ponte Felcino-Monte Molino Reach)

event. The results in Figure $7 \mathrm{a}-\mathrm{d}$ and Table IX indicate that both models can be confidently employed for flood forecasting for the 8-h lead time.

Figure $8 \mathrm{a}-\mathrm{d}$ shows the $12-\mathrm{h}$ lead time flood forecasts for storms observed at the Monte Molino downstream station (Figure 2). The travel time between the two stations is about $8 \mathrm{~h}$. MMM cannot be applied for forecasting here because the lead time is longer than the wave travel time. Thus, for the 12-h lead time forecasting, only ANN was employed. It is seen from Figure 8a-d that the model, in general, predicted each peak with a delay (Figure 8a, b and c). It over-predicted the first lower peak of the hydrograph, but slightly underestimated the higher peak (Figure $8 \mathrm{c}$ and $\mathrm{d}$ ). Table $\mathrm{X}$ gives the percentage of error for the cases shown in Figure $8 \mathrm{a}-\mathrm{d}$. On average, it had less than $10 \%$ error in forecasting the time to peak and also less error in the peak discharge. Its persistence coefficient in three cases is more than $60 \%$. These results indicate that the ANN can satisfactorily forecast floods with a lead time longer than the wave

Table IX. Percentage errors in peak discharge, $E_{Q p}$, time to peak, $E_{T p}$, and persistence coefficient $\left(C_{p}\right)$ for the 8-h lead time flood forecasts (Ponte Felcino-Monte Molino Reach)

\begin{tabular}{|c|c|c|c|c|c|c|}
\hline \multirow[t]{2}{*}{ Event } & \multicolumn{2}{|c|}{$\begin{array}{c}E_{Q p} \\
(\%)\end{array}$} & \multicolumn{2}{|c|}{$\begin{array}{l}E_{T p} \\
(\%)\end{array}$} & \multicolumn{2}{|c|}{$C_{p}$} \\
\hline & ANN & MMM & ANN & MMM & ANN & MMM \\
\hline February 1999 & $1 \cdot 7$ & $-6 \cdot 6$ & $0 \cdot 0$ & $0 \cdot 0$ & $0 \cdot 81$ & $0 \cdot 85$ \\
\hline April 1999 & 8.7 & $4 \cdot 2$ & $8 \cdot 3$ & -1.4 & 0.66 & 0.70 \\
\hline March 2000 & 1.8 & $-3 \cdot 4$ & $1 \cdot 3$ & $0 \cdot 0$ & $0 \cdot 34$ & 0.55 \\
\hline December 2000 & 0.4 & -9.3 & $-3 \cdot 2$ & -10.8 & 0.37 & 0.51 \\
\hline Average & $3 \cdot 2$ & $5 \cdot 9$ & $3 \cdot 2$ & $3 \cdot 1$ & 0.55 & 0.65 \\
\hline
\end{tabular}

travel time. This has important implications in that hydrologists will have sufficient time to warn authorities for minimizing flood damages long before the flood peak arrives at a downstream station.

\section{CONCLUSIONS}

The following conclusions are drawn from this study: (1) ANN outperformed RCM in predicting individual storm hydrographs observed in the Tiber river basin in Italy. When the flow-stage data is sufficient to train ANN, it can be confidently employed for individual storm predictions. (2) The results of sensitivity analysis indicate that when only flow-stage data measured at an upstream station is used as input, ANN can be cautiously employed for flood prediction at the downstream station if the lateral inflow to the river each is not significant. (3) The extrapolation error of ANN increases with the difference between the peak discharge used in training and that used in testing. (4) MMM cannot be employed for forecasting

Table X. Percentage errors in peak discharge, $E_{Q p}$, time to peak, $E_{T p}$, and persistence coefficient $\left(C_{p}\right)$ for the 12-h lead time flood forecasts by the ANN Model (Ponte Felcino-Monte Molino Reach)

\begin{tabular}{lrrr}
\hline Event & $\begin{array}{r}E_{Q p} \\
(\%)\end{array}$ & $\begin{array}{r}E_{T p} \\
(\%)\end{array}$ & $C_{p}$ \\
\hline February 1999 & -9.7 & $10 \cdot 7$ & 0.81 \\
April 1999 & 5.6 & 12.5 & 0.63 \\
March 2000 & $-6 \cdot 7$ & $6 \cdot 3$ & 0.41 \\
December 2000 & -6.9 & $-1 \cdot 1$ & 0.61 \\
Average & $7 \cdot 2$ & 7.7 & 0.62 \\
\hline
\end{tabular}



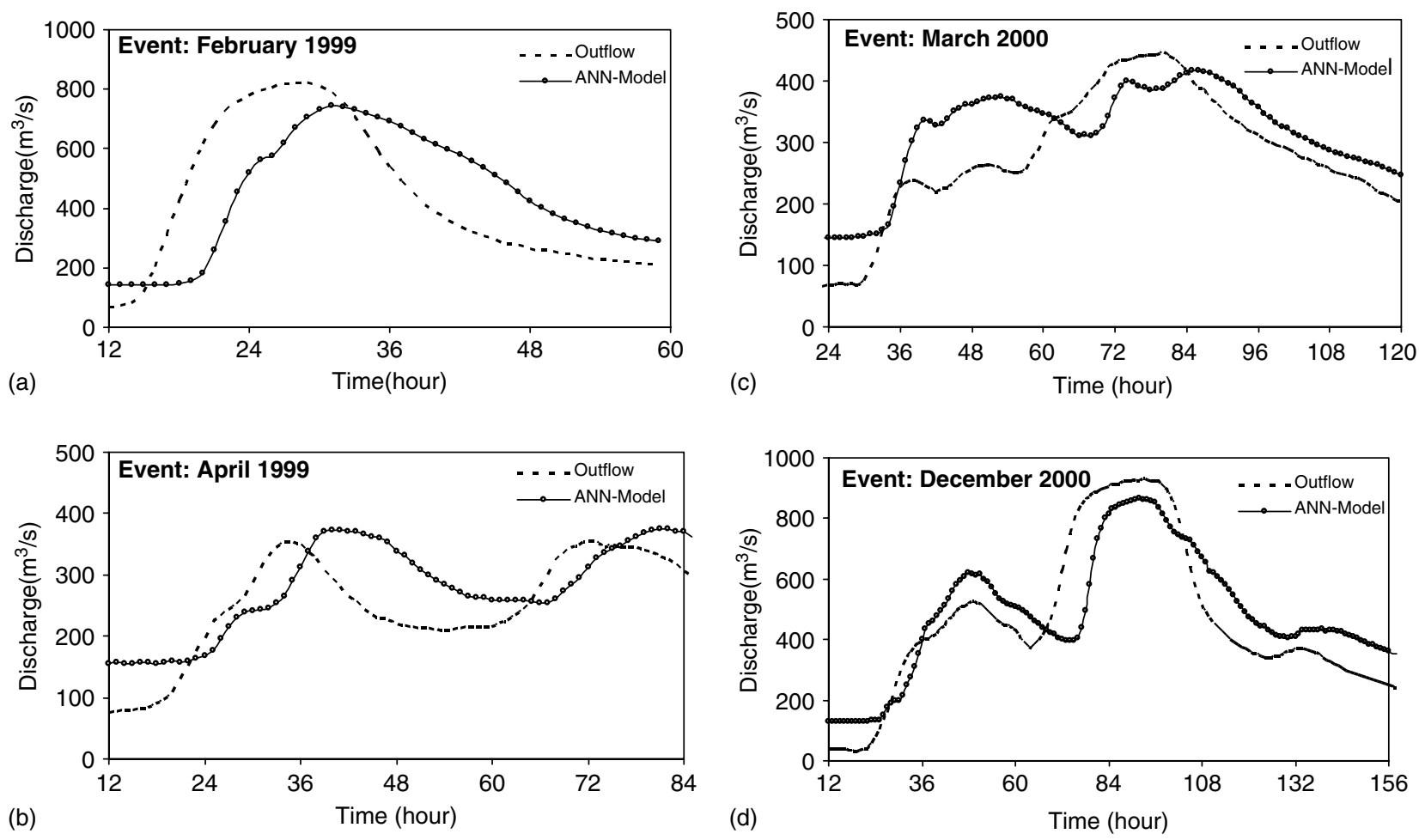

Figure 8. Forecasting storm hydrographs of (a) February 1999, (b) April 1999, (c) March 2000, and (d) December 2000 by ANN model with a 12-h lead time (Ponte Felcino-Monte Molino Reach)

if the lead time is greater than the wave travel time. (5) ANN can be employed for forecasting individual storm hydrographs for different lead times, such as 4-, 8or 12-h periods. (6) Although ANN outperformed MMM in forecasting with shorter lead times, the performances of both are comparable for longer lead times. Unlike MMM, ANN can be employed for forecasting individual storm hydrographs with lead times greater than the wave travel time.

It should be noted that the data used in this study for ANN prediction and forecasting are obtained from the upper Tiber river basin in Italy. Therefore, the conclusions of this study are specific to the data used and, consequently, to the upper Tiber river basin. This implies that before directly applying the ANN model developed in this study to a different basin, the model should be retrained with the data for that particular basin.

\section{ACKNOWLEDGMENTS}

The authors are thankful to the Department of Soil Conservation of the Umbria Region for providing part of the data; they are also grateful to Dr. Silvia Barbetta for her contribution in data processing.

\section{REFERENCES}

ASCE Task Committee. 2000a. Artificial neural networks in hydrology. I: preliminary concepts. Journal of Hydrologic Engineering, ASCE 5(2): $115-123$.

ASCE Task Committee. 2000b. Artificial neural networks in hydrology. II: hydrologic applications. Journal of Hydrologic Engineering, ASCE 5(2): $124-137$.
Barbetta S, Melone F, Moramarco T. 2004. A simple river stage forecasting model for sites without rating curve. In Applied Simulation and Modelling, Hamza MH (ed). IASTED Acta Press: Anaheim, CA; 207-212.

Barbetta S, Melone F, Moramarco T, Singh VP. 2003. Hydraulichydrologic components of an operational system for a dam management. In Watershed Hydrology, Singh VP, Yadava RN (eds). Allied Publishers: New Delhi; 252-262.

Boyle DP, Gupta HV, Sorooshian S, Koren V, Zhang Z, Smith M. 2001. Towards improved streamflow forecasts: the value of semi-distributed modeling. Water Resources Research 37(11): 2749-2759.

Cigizoglu HK. 2003. Estimation, forecasting and extrapolation of flow data by artificial neural networks. Hydrological Sciences Journal 48(3): 349-362.

Dawson WC, Wilby R. 1998. An artificial neural network approach to rainfall-runoff modeling. Hydrological Sciences Journal 43(1): 47-66. Fenton JD. 1999. Calculating Hydrographs from Stage Records, XXVIII IAHR Congress, Graz, Austria, 22-27 August 1999.

Franchini M, Lamberti P. 1994. A flood routing Muskingum type simulation and forecasting model based on level data alone. Water Resources Research 30(7): 2183-2196.

French MN, Krajewski WF, Cuykendall RR. 1992. Rainfall forecasting in space and time using a neural network. Journal of Hydrology 137: $1-31$

Henderson FM. 1966. Open Channel Flow. MacMillan: New York.

Imrie CE, Durucan S, Korre A. 2000. River flow prediction using artificial neural networks: generalization beyond the calibration range. Journal of Hydrology 233: 138-153.

Kitanidis PK, Bras R. 1980. Real-time forecasting with a conceptual hydrologic model. 2. Applications and results. Water Resources Research 16(6): 1034-1044

Laio F, Porporato A, Revelli R, Ridolfi L. 2003. A comparison of nonlinear flood forecasting methods. Water Resources Research 39(5): 1129. Michaud JD, Sorooshian S. 1994. Comparison of simple versus complex distributed runoff models on a midsize semiarid watershed. Water Resources Research 30(3): 593-605.

Moramarco T, Singh VP. 2000. A practical method for analysis of river waves and for kinematic wave routing in natural channel networks. Hydrological Processes 14: 51-62.

Moramarco T, Singh VP. 2001. Simple method for relating local stage and remote discharge. Journal of Hydrologic Engineering, ASCE 6(1): $78-81$. 
Moramarco T, Saltalippi C, Singh VP. 2004. Estimating the crosssectional mean velocity in natural channels using Chiu's velocity distribution. Journal of Hydrologic Engineering 9(1): 42-50.

Moramarco M, Barbetta S, Melone F, Singh VP. 2005. Relating local stage and remote discharge with significant lateral inflow. Journal of Hydrologic Engineering, ASCE 10(1):58-69.

Rajurkar MP, Kothyari UC, Chaube UC. 2002. Artificial neural networks for daily rainfall-runoff modeling. Hydrological Sciences Journal 47(6): 865-877.

Raudkivi AJ. 1979. Hydrology: An Advanced Introduction to Hydrological Processes and Modeling. Pergamon: New York.

Tayfur G. 2002. Artificial neural networks for sheet sediment transport. Hydrological Sciences Journal 47(6): 879-892.

Tokar AS, Johnson PA. 1999. Rainfall-runoff modeling using artificial neural networks. Journal of Hydrologic Engineering, ASCE 4(3): $232-239$.

Tokar SA, Markus M. 2000. Precipitation-runoff modelling using artificial neural networks and conceptual models. Journal of Hydrologic Engineering, ASCE 5(2): 156-161.

U.S. Army Corps of Engineers. 1998. HEC-RAS: River Analysis System: Application Guide. Hydrologic Engineering Center: Davis, CA.

\section{APPENDIX NOTATION}

The following symbols are used in this paper:

$A=$ flow area;

$A_{u}, A_{d}=$ upstream and downstream effective flow area; $c=$ wave celerity;

$c_{0}, c_{1}, c_{2}=$ Muskingum model coefficients;

$h=$ water level;

$h_{d}=$ water level recorded at the downstream section;

$K=$ attenuation parameter for the peak discharge;
$L=$ river reach length;

$p_{1}=$ parameter in the lateral inflow component;

$p=$ number of output neurons;

$P=$ number of training patterns.

$q=$ lateral inflow per unit length;

$q_{p}=$ lateral inflow per unit length during the time interval $\left(t_{p}-T_{L}, t_{p}\right)$

$Q=$ discharge;

$Q_{u}, Q_{d}=$ upstream and downstream discharge;

$Q_{u}^{p}=$ upstream peak discharge;

$Q^{*}=$ upstream peak discharge attenuation;

$t=$ time;

$t_{b}, t_{p}=$ time when base flow and peak stage occurred at the downstream section;

$t_{i}=$ component of a target output vector $\boldsymbol{T}$;

$T_{L}=$ wave travel time;

$v_{i j}=$ weight from the $i$ th neuron in the previous layer to the $j$ th neuron in the current layer;

$x=$ distance along the river reach;

$y_{i}=$ component of a network output vector $\boldsymbol{Y}$;

$\alpha, \beta=\mathrm{RCM}$ model parameters;

$\Delta t^{*}=$ time interval equal to one fifth of the time to peak of the inflow hydrograph;

$\Delta t=$ Muskingum time step simulation;

$\varepsilon_{Q_{p}}=$ percentage error in peak discharge;

$\varepsilon_{t_{p}}=$ percentage error in time to peak;

$\delta=$ learning rate. 